\title{
PELATIHAN PEMBUATAN ILUSTRASI FOTO DIGITAL DAN PORTFOLIO BERBASIS ONLINE BAGI SISWA-SISWI SMK IT AL HIDAYAH 2 JAKARTA
}

\author{
Sulistiyo Wibowo $^{1^{*}}$, Yusuf Nurachman ${ }^{2}$, Nofiandri Setyasmara ${ }^{3}$ \\ Penerbitan/Fotografi, Politeknik Negeri Media Kreatif, Indonesia \\ sulistiyo@polimedia.co.id-1,yusuf@polimedia.co.id-2, nofiandri@polimedia.co.id-3
}

\begin{abstract}
ABSTRAK
Setiap keilmuan yang kita miliki seyogyanya dapat bermanfaat bagi lingkungan disekitar kita. Minimal untuk orang terdekat dan lingkungan tempat kita tinggal. Dalam kaitannya dengan pengabdian masyarakat kali ini kami sebagai tim pengabdian ingin membertikan sesuatu yang bermanfaat bagi masyarakat khususnya adik-adik dari sekolah menengah kejuruan yang terletak tidak terlalu jauh dari tempat penulis mengajar.

Pengabdian ini adalah bentuk penularan ilmu terhadap siswa-siswi yang memiliki semangat belajar fotografi dan editing pasca pemotretan (baca : foto editing) namun terkendala sarana dan prasarana serta pengajar yang mampu memberikan materi tersebut. Kebetulan kami adalah adalah praktisi dan akademisi di bidang tersebut maka selayaknyalah kami dapat memberikan pemahaman dan praktek mengenai pembelajaran tersebut, walau mungkin dari waktu tidak semaksimal yang biasa kami berikan ketika mengajar di bangku perkuliahan.

Semoga dengan rencana pelatihan ini nantinya akan tercipta individu-individu siap kerja dan mampu bersaing serta percaya diri di dunia luar sana. Besar harapan penulis agar pelatihan ini dapat berkesinambuingan untuk menjaring lebih banyak anak muda yang potensial dan mau belajar untuk kemudian menularkan kembali ilmunya ke masyarakat luas.
\end{abstract}

Kata Kunci: Editing; Fotografi; Kompetensi

\begin{abstract}
Every science that we have should be useful for the environment around us. At least for the closest people and the environment where we live. In relation to this community service, as a community service team, we want to provide something that is useful for the community, especially for younger siblings from a vocational high school which is located not too far from where the author teaches. This service is a form of transmitting knowledge to students who have a passion for learning photography and post-shooting editing (read: photo editing) but are constrained by facilities and infrastructure as well as teachers who are able to provide the material. Incidentally, we are practitioners and academics in this field, so we should be able to provide understanding and practice regarding this learning, even though it may not be as much as what we usually give when teaching in lectures. Hopefully this training plan will create individuals who are ready to work and able to compete and confident in the outside world. The author hopes that this training can be continuous to attract more young people who are potential and willing to learn and then transmit their knowledge back to the wider community.
\end{abstract}

Keywords: Editing; Photography; competence

\section{A. LATAR BELAKANG}

Kebutuhan skill editing foto pasca pemotretan saat ini sangat dibutuhkan karena dunia fotografi saat ini sudah beralih ke teknologi digital. Hal ini disebabkan dengan 
kemunculan era fotografi digital beberapa tahun kebelakang dan teknologi yang menyertainya. Seperti kita ketahui saat ini sangat mudah unruk menghasilkan sebuah foto dengan cepat dan memiliki kualitas yang relatif baik dibandingkan pada era tahun 90an misalnya. Dahulu dunia fotografi (baca: kamera) bisa dikatakan begitu begitu mahal dan telepon seluler pun belum dilengkapi kamera. Namun sekarang semuanya berubah dengan harga yang relatif terjangkau, Hal diatas adalah secuil mengenai sekelumit perkembangan fotografi yang secara sadar atau tidak kemudahannya kita rasakan sekarang, baik yang dahulu menggunakan kamera analog atau pengguna yang langsung merasakan nikmatnya kamera digital saat ini tanpa pernah merasakan rumitnya menggunakan kamera analog.

Namun dalam konteks pengabdian ini penulis tidak akan membahas terlalu dalam mengenai masalah perkembangan tersebut. Menjadi fokus utama adalah bahwa hasil dari pemotretan tersebut kadangkala memerlukan sedikit bahkan banyak sentuhan (retouching) sebuah software editing. Baik yang bersifat soft editing (mudah) hingga advance editing (sulit). Sehingga membuat foto menjadi lebih artistik dengan bantuan software tertentu. Dalam pengolahannya siswa-siswai diajak untuk mempelajari software berbasis vector (adobe Ilustrator) yang pada dasarnya berbeda dengan pengolahan gambar bitmap.

Penerapan atau pengaplikasian teori ke dalam praktikum persentasenya masih sangat kurang khususnya dalam pembelajaran foto editing berbasis vector dan bitmap di sekolah SMK. Walaupun ada masih sebatas pada tahap dasar belum pada tahap mahir. Oleh karena itu rumusan pengabdian ini lebih menitikberatkan kepada mengolah /kemampuan siswa dalam teknis editing yang ideal,efektif dan memiliki nilai seni.

\section{B. METODE PELAKSANAAN}

Setelah melihat dan menimbang permasalahan dan kebutuhan. Maka Solusi yang tepat dalam pengembangan kemampuan siswa/i SMK IT Al HIDAYAH II khususnya yang berkenaan dengan pelajaran pasca fotografi digital adalah dengan praktikum langsung menggunakan perangkat lunak editing foto dan pengolah gambar berbasis vektor yang umum digunakan di masyarakat dan industri saat ini yaitu Adobe Photoshop dan Adobe Ilustrator dengan capaian tingkat mahir.

Selain lebih menarik minat siswa, praktikum ini lebih menekankan kepada kreatifitas para siswa dalam mengolah foto sedemikian rupa sehingga tampak menarik dan artistik.

Metode pelaksanaan pelatihan ini dilaksanakan di dalam lingkungan sekolah tepatnya di dalam ruangan kelas atau lab pada tanggal 28-29 Juni 2021. Berikut adalah beberapa rincian pelaksanaan kegiatan pelatihan tersebut :

\section{Audiens/Peserta}

Siswa dan Siswi SMK IT Al HIDAYAH II yang beralamat di jalan Jalan Kesatuan No.47 Jagakarsa, Jakarta Selatan. Dengan jumlah perserta sebanyak kurang lebih 20 orang terdiri dari 12 siswa putra dan 8 siswi putri kelas $\mathrm{X}$.

\section{Materi}

\section{Adobe Photoshop}

- Basic Document

- Basic selection

- Modifier selection

- Stroke selection

- Solid Color, Gradient, Transparant

- Layering 
- Channel

- Color Correction (brightness, contras, level, curves, etc)

- Image retouching ( healing, stamp, patch)

- Image modifier (refine edge, color range, action)

\section{HTML, Wordpress, WIX}

Media pembuat web berbasis online salah satunya untuk kebutuhan pembuatan portfolio.

\section{HASIL DAN PEMBAHASAN}

Hasil dari pelatihan ini harapannya adalah meningkatnya kompetensi dan keahlian siswa-siswi khususnya dari segi materi yang kami ajarkan. Walaupun kami menyadari bahwa kendala pandemi covid 19 yang belum mereda serta waktu yang terbatas menjadi tantangan utama kami dalam memberikan pengajaran. Berikut adalah produk yang mereka hasilkan dalam proses pembelajaran yang berlangsung selama dua hari tersebut :

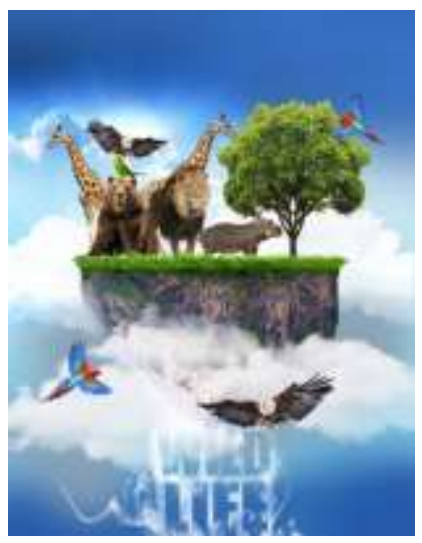

Gambar 1. Contoh project yang akan dikerjakan para peserta
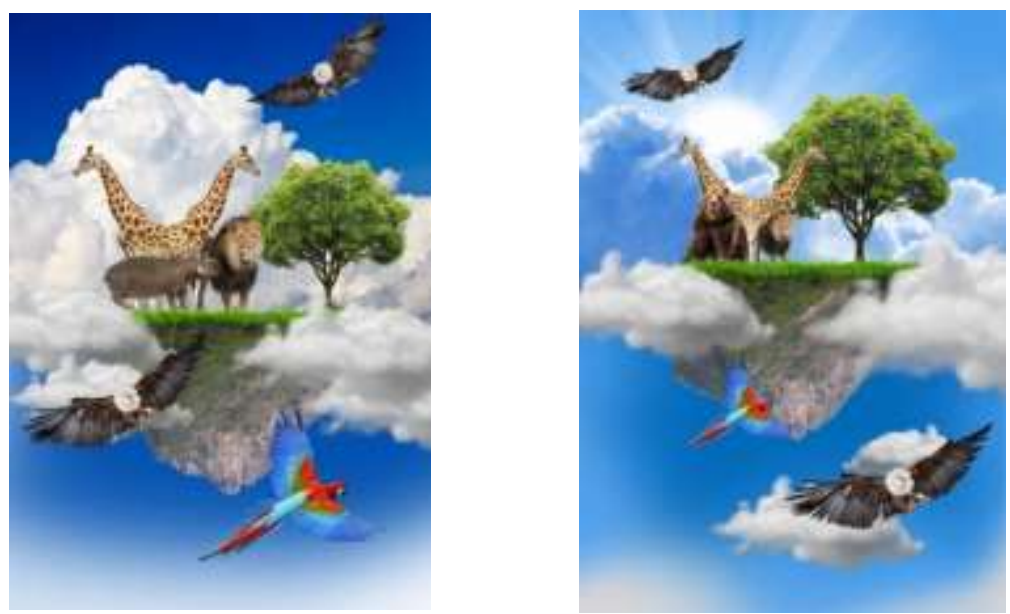

Gambar 2. Hasil project yang telah dikerjakan para peserta 
60 | PEKAMAS (Pengabdian Kepada Masyarakat) | Vol. 1, No.2, Desember 2021, hal. 57-62

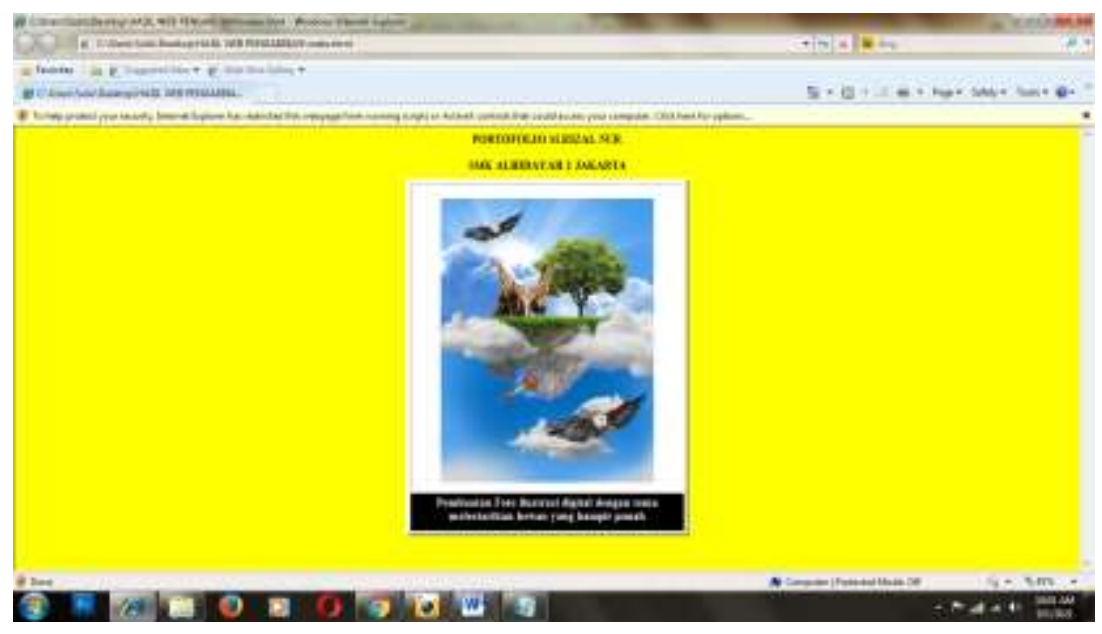

Gambar 3. Hasil upload portfolio dalam bentuk HTML

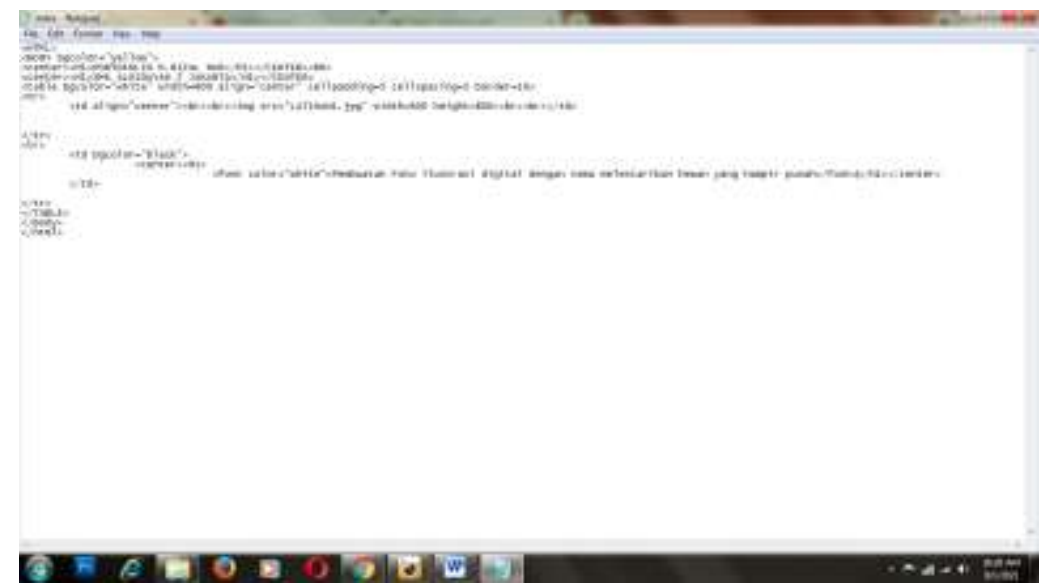

Gambar 4. Hasil coding dalam bentuk HTML

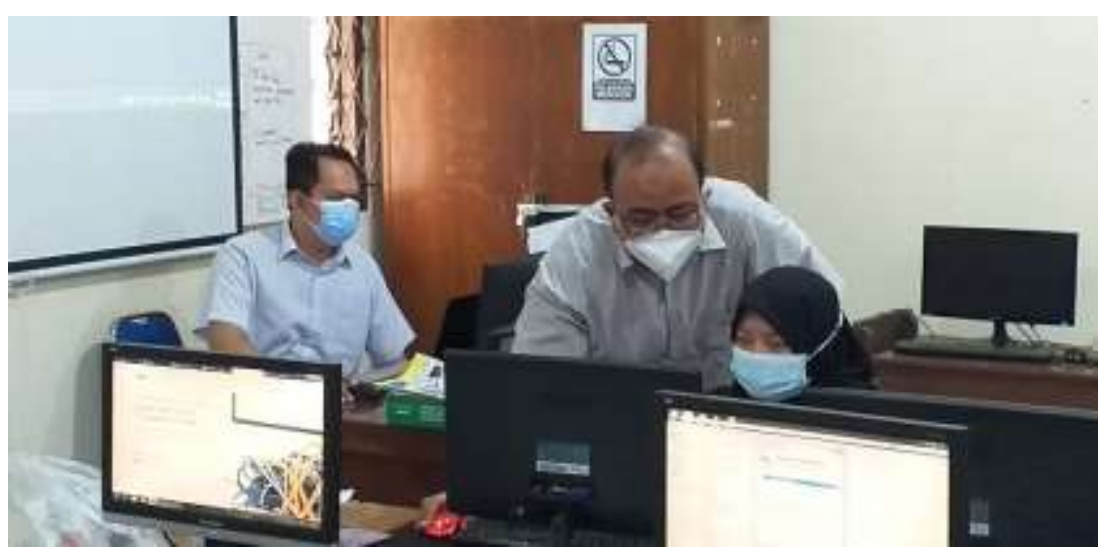

Gambar 5. Proses pengajaran 


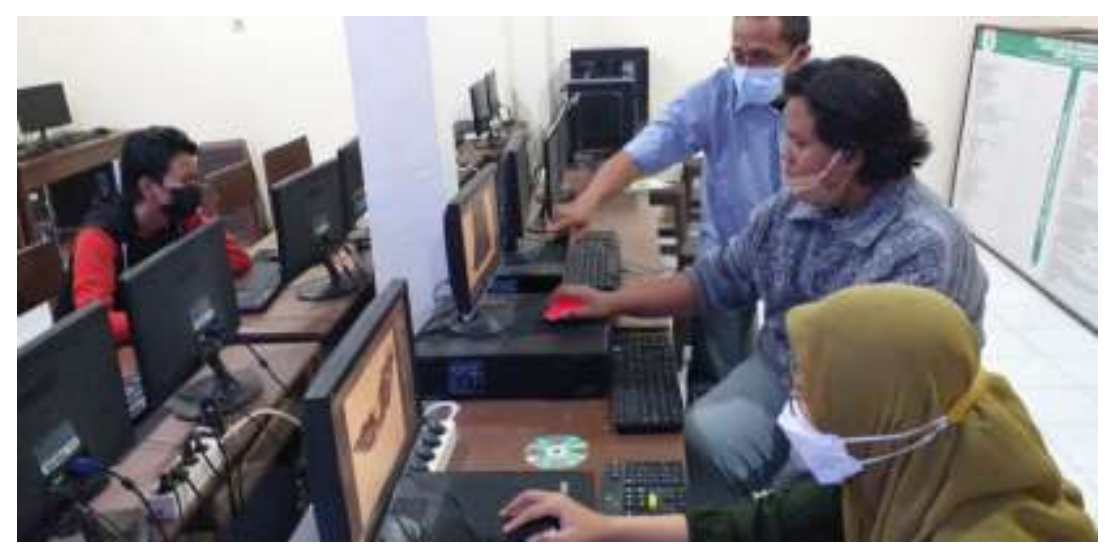

Gambar 6. Proses pengajaran

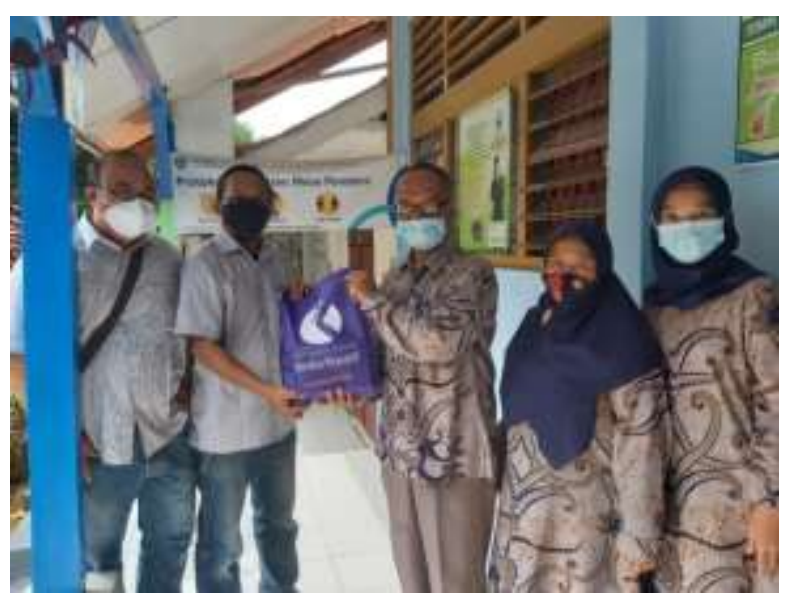

Gambar 7. Pemberian sumbangan buku

\section{SIMPULAN DAN SARAN}

Secara hasil dapat dikatakan cukup memuaskan walau masih ada kekurangan khususnya dalam layout foto dan pemahaman pembuatan web portfolio menggunakan HTML. Namun apapun hasilnya kami sebagai tim pengajar khususnya merasa bangga kepada adik-adik kita ini karena pelatihan ini diselenggarakan ketika masa pandemi covid 19 sedang tinggi pada akhir bulan Juni.Mereka dengan semangatnya mengikuti pelatihan ini dari awal hingga selesai. Pihak sekolah pun merasa puas dan berterimakasih atas pelatihan ini serta berharap dapat terus menjalin kerjasama dengan Polimedia dalam bentuk pelatihan serupa yang dapat meningkatkan kompetensi siswa-siswi khususnya.

Secara pelaksanaan dapat dikatakan cukup baik dan memuaskan namun diharapkan pihak sekolah dapat meningkatkan pula proses pengajaran mengenai materi terkait agar para siswanya dapat memiliki kompetensi lebih baik dari yang sudah kami ajarkan pada pelatihan ini.

\section{UCAPAN TERIMA KASIH}

Terimakasih kami ucapkan kepada P3M Politenik Negeri Media Kreatif yang telah memberikan kesempatan dan kepercayaan kepada kami untuk melakukan salah satu tri dharma perguruan tinggi ini. Terimakasih juga kepada SMK Alhidaya 2 Jakarta yang telah bekerjasama dan menerima kami dalam pelatihan ini, semoga kedepannya kami dapat bekerjasama lebih lanjut untuk meningkatkan komptensi siswa siswi atau guru pengajar di sana. 
62 | PEKAMAS (Pengabdian Kepada Masyarakat) | Vol. 1, No.2, Desember 2021, hal. 57-62

\section{DAFTAR RUJUKAN}

Hendratman, Hendi (2011) The Magic Of Adobe Illustrator, Informatika, Bandung, Effendhy, Asep (2011) 101 Manipulasi Photoshop, MediaKom, Yogyakarta

Madcom \& Andi (2013) You Can Do It With Photoshop, Penerbit Andi \& Madcom, Yogyakarta. Paulus, Edison (2011) Buku Saku Fotografi, PT. Elex Media Komputindo, Jakarta

Soekojo, Makarios (2007) Dasar Fotografi Digital, Penerbit PT. Prima Infosarana Media, Jakarta Tjin, Enche (2011) Lighting Itu Mudah, Bukune, Jakarta

Jason Beaird, James George (2017) The principles of Beautiful Web Design. Penerbit Andi, Yogyakarta. 